\title{
Combined interventions to reduce HIV incidence in KwaZulu-Natal: a modelling study
}

\author{
Stéphanie Blaizot ${ }^{1,2,3,4^{*}}$, Helena Huerga ${ }^{5}$, Benjamin Riche ${ }^{1,2,3,4}$, Tom Ellman ${ }^{6}$, Amir Shroufi ${ }^{6}$, \\ Jean-François Etard ${ }^{5,7}$ and René Ecochard ${ }^{1,2,3,4}$
}

\begin{abstract}
Background: Combined prevention interventions, including early antiretroviral therapy initiation, may substantially reduce HIV incidence in hyperendemic settings. Our aim was to assess the potential short-term impact of combined interventions on HIV spreading in the adult population of Mbongolwane and Eshowe (KwaZulu-Natal, South Africa) using sex- and age-specific scenarios, and age-targeted interventions.

Methods: A mathematical model was used with data on adults (15-59 years) from the Mbongolwane and Eshowe HIV Impact in Population Survey to compare the effects of various interventions on the HIV incidence rate. These interventions included increase in antiretroviral therapy (ART) coverage with extended eligibility criteria, increase in voluntary medical male circumcision (VMMC), and implementation of pre-exposure prophylaxis (PrEP) among women.

Results: With no additional interventions to the ones in place at the time of the survey (ART at CD4 $<350$ and VMMC), incidence will decrease by $24 \%$ compared to the baseline rate. The implementation of "ART at CD $4<500$ " or "ART for all" would reduce further the incidence rate by additional $8 \%$ and $15 \%$ respectively by 4 years and $20 \%$ and $34 \%$ by 10 years. Impacts would be higher with age-targeted scenarios than without.

Conclusions: In Mbongolwane and Eshowe, implementation of the new South African guidelines, recommending ART initiation regardless of CD4 count, would accelerate incidence reduction. In this setting, combining these guidelines, VMMC, and PrEP among young women could be an effective strategy in reducing the incidence to low levels.
\end{abstract}

Keywords: HIV, Mathematical models, Antiretroviral therapy, Male circumcision, Pre-exposure prophylaxis, South Africa

\section{Background}

South Africa has one of the highest HIV prevalence in the world, estimated at $18.8 \%$ among adults (15-49 years) in 2012 [1]. However, the HIV epidemic in the country is heterogeneous and KwaZulu-Natal (KZN) has the highest HIV prevalence of the nine provinces in South Africa (estimated at $27.9 \%$ in 2012) [1].

UNAIDS set "90-90-90" targets (i.e. 90\% of the HIVpositive diagnosed, $90 \%$ of those diagnosed under treatment, and $90 \%$ of those under treatment virally suppressed) to be achieved by 2020 [2]. However, challenges in the HIV cascade of care remain and,

\footnotetext{
* Correspondence: sblaizot@yahoo.fr

'Service de Biostatistique, Hospices Civils de Lyon, F-69003 Lyon, France

${ }^{2}$ Université de Lyon, F-69000 Lyon, France

Full list of author information is available at the end of the article
}

particularly, levels in the cascade vary greatly by sex and age [1, 3-6]. Moreover, voluntary medical male circumcision (VMMC) coverage and demand vary with age [1,7], with the highest levels found among young individuals. Finally, young women are disproportionately affected by HIV $[8,9]$ and a prevention intervention such as pre-exposure prophylaxis (PrEP) could be an additional tool to reduce HIV incidence in this subpopulation.

In the present study, we assessed the potential impact of scaling-up antiretroviral therapy (ART) with extended ART eligibility as well as combinations of ART with VMMC and PrEP on HIV incidence among adults (15-59 years old) in Mbongolwane and Eshowe, KZN (South Africa), using age-specific coverage targets as well as age-targeted scenarios, by 4 and 10 years. 


\section{Methods}

Study setting and the Mbongolwane and Eshowe HIV Impact in Population Survey (MHIPS)

Mbongolwane is a rural area in $\mathrm{KZN}$ and Eshowe the main town of the municipality. According to the 2011 Census [10], 61,179 people aged 15 to 59 were living in 25,106 households in the area covered by the survey. The KZN Department of Health over the last ten years has conducted an HIV programme in the province that includes HIV testing, HIV care, and ART. Since 2011, in the area of Mbongolwane and Eshowe, Médecins Sans Frontières (MSF) supports the Department of Health HIV and tuberculosis programmes implementing largescale HIV testing activities and decentralisation of ART initiation, including nurse-initiated and managed ART with the aim of decreasing HIV and tuberculosis incidence, morbidity and mortality.

The Mbongolwane and Eshowe HIV Impact in Population Survey (MHIPS) is a cross-sectional population-based survey conducted from July to October 2013 (i.e. after MSF implementation began). The primary objective of the MHIPS was to assess ART coverage among HIV infected individuals in need of ART in Mbongolwane and Eshowe. The secondary objectives included determining HIV prevalence, HIV incidence, and coverage of HIV services.

The design and procedures of the survey has been previously described [11]. Briefly, a cluster sampling and geospatial random selection was used to identify the households visited. Persons aged 15-59 years living in the area were eligible. Face-to-face interviews were carried out followed by rapid HIV testing on site and blood collection for CD4 count, ART levels, and viral load in HIV-positive cases. Socio-demographic information were collected on all the household members using a household questionnaire and socio-demographic, behavioural, and medical information on each participant were collected using an individual questionnaire.

In total 2377 households were included, 6688 individuals were eligible and 5649 were included $(62 \%$ were women) [11]. Overall HIV prevalence was 25.2\%, higher in women than in men (30.9\% vs. $15.9 \%)$. Based on ART detection in blood, ART coverage among those eligible according to the national guidelines at the time of the survey was $75.0 \%$, higher in women than in men $(78.5 \%$ vs. $63.9 \%)$ and increased with age $(52.2 \%$ in younger than 25 years to $84.3 \%$ in $35-59$ years). ART coverage among all HIV-positive individuals was $53.1 \%$.

\section{Model and assumptions}

A previously developed compartmental model [12, 13] was used to describe HIV transmission, the untreated disease progression, and ART use in the adult population of Mbongolwane and Eshowe, based on the MHIPS data. The model splits the population into compartments according to sex, age (45 one-year strata from 15 to 59 years), and HIV status: HIV-negative (or susceptible) individuals (compartment S), untreated HIVpositive individuals with CD4 cell count $>350$ cells $/ \mathrm{mm}^{3}$ (compartment $\mathrm{I}_{1}$ ), untreated HIV-positive individuals with CD4 cell count $\leq 350$ cells $/ \mathrm{mm}^{3}$ (compartment $\mathrm{I}_{2}$ ), and HIV-positive individuals on ART (compartment T). The model parameters include: i) the force of infection; ii) the "immunosuppression rate", i.e. the rate at which an individual moves from $>350$ to $\leq 350$ cells $/ \mathrm{mm}^{3}$ CD4 cell count; iii) the "treatment rate" or the ART initiation rate; and, iv) the mortality rates. The estimates of the model parameters by sex and age group (15-24, 25-34, 35-59 years) and the estimates of the distributions of the population among the compartments by sex, age, and HIV status were based on the MHIPS data using a methodology described elsewhere [12] (see Additional file 1). We assumed that individuals in compartments $S$, $\mathrm{I}_{1}$, and $\mathrm{T}$ had the same risk of death whereas individuals in compartment $\mathrm{I}_{2}$ had an additional risk of death due to AIDS, and used mortality rates from another region in KwaZulu-Natal [14]. A sensitivity analysis on values of mortality rates in individuals in compartments $\mathrm{I}_{1}$ and $\mathrm{T}$ was performed using values of mortality rates among individuals in compartment $\mathrm{I}_{2}$ (rather than among HIVnegative individuals): the mortality rates in individuals in compartments $I_{1}$ and $T$ were varied with values being one tenth, one fifth, or half those in individuals in compartments $\mathrm{I}_{2}$. Table 1 shows the values of model parameters by sex and age group.

Baseline proportions of circumcised men among HIVnegative men by age group were calculated on the MHIPS data: 26\%, 21\%, and 19\% of HIV-negative men were circumcised in the age groups 15-24, 25-34, and 35-59 years respectively (overall: $22 \%$ ). The protective effect of circumcision was assumed to reduce femalemale transmission by $60 \%$ [15-17]. We assumed that PrEP was not available and not used at the time of the survey by HIV-negative women. In our PrEP scenarios, the protective effect of PrEP was assumed to reduce male-female transmission by $50 \%$ based on metaanalysis results [18].

Information on the population viral load was included to the force of infection (see Additional file 1). In particular, the infectiousness of individuals with viral load $<1000$ copies $/ \mathrm{mL}$ in each compartment was assumed to be reduced by $96 \%$ [19]. Based on the MHIPS data, the proportion of individuals with viral load $<1000$ copies/mL was $24 \%$ and $14 \%$ in compartment $I_{1}, 5 \%$ and $6 \%$ in compartment $I_{2}$, and $93 \%$ and $92 \%$ in compartment $\mathrm{T}$, for women and men, respectively. These values were considered constant over time. 
Table 1 Infection, immunosuppression, treatment and mortality rates (per 100 person-years) used in the model

\begin{tabular}{|c|c|c|}
\hline Transition rates & Women & Men \\
\hline \multicolumn{3}{|l|}{ Infection rate } \\
\hline $15-24$ years & $3.0[2.1 ; 4.2]$ & $0.3[0.1 ; 0.9]$ \\
\hline 25-34 years & $6.6[4.5 ; 9.5]$ & $1.9[0.9 ; 4.2]$ \\
\hline $35-59$ years & $1.0[0.5 ; 2.0]$ & $2.2[1.1 ; 4.5]$ \\
\hline \multicolumn{3}{|c|}{ Immunosuppression rate } \\
\hline $15-24$ years & $15.4[7.8 ; 30.4]$ & $13.8[1.8 ; 105.4]$ \\
\hline $25-34$ years & $6.6[2.9 ; 15.1]$ & $25.4[11.1 ; 58.4]$ \\
\hline $35-59$ years & $12.2[6.0 ; 25.1]$ & $13.6[4.2 ; 43.8]$ \\
\hline \multicolumn{3}{|l|}{ Treatment rate } \\
\hline $15-24$ years & $60.9[41.5 ; 89.5]$ & $10.0[1.3 ; 76.1]$ \\
\hline $25-34$ years & $72.6[55.1 ; 95.8]$ & $38.6[23.9 ; 62.3]$ \\
\hline $35-59$ years & $89.9[68.3 ; 118.2]$ & $56.2[36.4 ; 86.7]$ \\
\hline \multicolumn{3}{|c|}{ Mortality rates for individuals in compartments $S, I_{1}$, and $T$} \\
\hline $15-24$ years & 0.12 & 0.16 \\
\hline $25-34$ years & 0.34 & 0.53 \\
\hline $35-44$ years & 0.23 & 0.61 \\
\hline $45-59$ years & 0.67 & 2.20 \\
\hline \multicolumn{3}{|c|}{ Mortality rates for individuals in compartment $I_{2}$} \\
\hline $15-24$ years & 2.52 & 3.90 \\
\hline $25-34$ years & 6.58 & 9.85 \\
\hline $35-44$ years & 6.76 & 5.59 \\
\hline $45-59$ years & 8.71 & 8.75 \\
\hline
\end{tabular}

The infection, immunosuppression, and treatment rates were estimated using the MHIPS data whereas the mortality rates stemmed from reference [14]. Compartment S: HIV-negative individuals; compartment $\mathrm{I}_{1}$ : untreated HIVpositive individuals with $\mathrm{CD} 4$ cell count $>350$ cells $/ \mathrm{mm}^{3}$; compartment $\mathrm{I}_{2}$ : untreated HIV-positive individuals with CD4 cell count $\leq 350$ cells $/ \mathrm{mm}^{3}$; compartment T: HIV-positive individuals on ART

\section{Interventions modelled}

Various interventions were modelled with different scenarios:

No change in baseline interventions. Here, all rates (particularly, treatment and circumcision rates) were considered stable over the simulation time, i.e. equal to the values estimated from the survey. Baseline interventions correspond to the interventions at the time of the survey (i.e. ART at CD4 $<350$ and VMMC at $22 \%$ coverage among adult HIV-uninfected men).

ART intervention. This intervention explored the impact of changing the ART initiation strategy and increasing the coverage. For this intervention, two ART initiation recommendations were compared: i) the WHO 2013 guidelines (called in short "ART at CD4<500"): CD4 $\leq 500$ cells $/ \mathrm{mm}^{3}$ plus PMTCT option B + (i.e., lifelong ART for all HIV-positive pregnant and breastfeeding women whatever their CD4 cell count); and, ii) the WHO 2015 guidelines (called in short "ART for all"): treatment for all whatever the CD4 cell count. For "ART at CD4<500" intervention, the scenario assumed that the ART coverage (among eligible individuals) increased from $41 \%$ to $55 \%$ in the $15-24$ age group, from $56 \%$ to $75 \%$ in the $25-34$ age group and from $77 \%$ to $85 \%$ in the $35-59$ age group within the first four years (overall coverage: $81 \%$ ). For "ART for all" intervention, the scenario assumed that the ART coverage (among eligible individuals) increased from $30 \%$ to $50 \%$ in the $15-24$ age group, from $46 \%$ to $70 \%$ in the $25-34$ age group and from $67 \%$ to $80 \%$ in the 35-59 age group within the first four years (overall coverage: $73 \%$ ). To do this, a transition rate was added between compartments $I_{1}$ and $T$ and its value was supposed to increase linearly over the first year and finally be proportional to the value of the rate between compartments $\mathrm{I}_{2}$ and T. For "ART at CD4<500", this transition rate was multiplied by the proportion of individuals with CD4 cell counts $\leq 500$ cells $/ \mathrm{mm}^{3}$ or pregnant or breastfeeding HIV-positive women (proportions stemming from the MHIPS data).

Although HIV-positive individuals initiating ART were assumed to remain on ART during the whole period of simulation, we assumed that $93 \%$ of women and $92 \%$ of men on ART had a viral load $<1000$ copies/mL (and thus had reduced infectiousness). A sensitivity analysis was performed assuming an annual drop-out from ART of $1.5 \%$ [20] or 5\% [21].

Voluntary medical male circumcision (VMMC). Two scenarios were considered for this intervention. The first scenario ("non-targeted VMMC" scenario) assumed a slight increase in the proportion of circumcised HIV-negative men with age-specific targets: from $26 \%$ to $35 \%$ in the $15-24$ age group, from $21 \%$ to $25 \%$ in the $25-34$ age group, and from $19 \%$ to $20 \%$ in the 35-59 age group (overall proportion: from $22 \%$ to $30 \%$ ). The second scenario ("targeted VMMC" scenario) focused on the 15-24 age group with a high increase in the proportion of circumcised HIV-negative men: from $26 \%$ to $70 \%$ (overall proportion: from $22 \%$ to $55 \%$ ). In these scenarios, proportions were agespecific with a linear increase within the first four years and stable thereafter, and took ageing into account. Pre-exposure prophylaxis (PrEP) in women. Three scenarios were considered for this intervention: a) "non-targeted PrEP" scenario: use of PrEP at 15\% in the $15-24$ age group, $10 \%$ in the $25-34$ age group, and $5 \%$ in the 35-59 age group (overall proportion: 10\%); b) "targeted PrEP" scenario at low level: $20 \%$ of women aged 15-24 years use PrEP (overall proportion: 10\%); and c) "targeted PrEP" scenario at medium level: 40\% of women aged 15-24 years use PrEP (overall proportion: $20 \%$ ). In these scenarios, proportions were 
age-specific with a linear increase within the first four years and stable thereafter, and took ageing into account.

Combined interventions. "ART at $C D 4<500$ " and "ART for all" interventions were combined with VMMC and PrEP separately and jointly using both the non-targeted and age-targeted scenarios.

These interventions were compared with respect to different outcomes: the incidence rate, the population viral load suppression, and the prevalence. Population viral load suppression was defined as the proportion of HIV-positive subjects with a viral load $<1000$ copies/ $\mathrm{mL}$ (with the use of the compartment-specific proportions given in "Model and assumptions"). We reported reduction in incidence rate (in percentage) compared to the baseline rate (date at which the MHIPS was performed), unless otherwise specified. Moreover, ratios between the reduction in HIV incidence and the additional number of person-years on ART, or additional number of circumcisions or PrEP were calculated to compare results of "ART at CD $<<500$ " and "ART for all", and targeted and non-targeted scenarios.

\section{Results}

With no additional interventions to the ones in place at the time of the survey (i.e. ART at CD4 $<350$ and VMMC at $22 \%$ coverage among adult HIV-uninfected men), the HIV incidence rate would be reduced by $24 \%$ (from 2.25 to 1.70 per 100 person-years) by 4 years and by $25 \%$ (to 1.68 per 100 person-years) by 10 years. The reduction in HIV incidence would be higher in women than in men by 4 years ( $27 \%$ vs. $11 \%$ respectively compared to the baseline rate; Table 2). After a decrease, the HIV incidence in men would slighlty increase by 10 years due to a saturation effect given that ART was limited to HIV-positive women and men with CD4 $<350$ cells $/ \mathrm{mm}^{3}$. The reduction in HIV incidence would be higher in age groups $15-24$ and 25-34 years than in the age group $35-59$ years $(31 \%$ and $29 \%$ vs. $18 \%$ respectively by 4 years, Table 2 , and by $38 \%$ and $37 \%$ vs. $17 \%$ by 10 years).

Under this scenario, the prevalence would remain relatively stable over the simulation time (from $26.2 \%$ to $26.5 \%$ and $26.4 \%$ by 4 years and 10 years respectively) whereas the ART coverage among individuals with CD $4<350$ would increase from $77 \%$ to $91 \%$ and $93 \%$ by 4 and 10 years respectively, the ART coverage among all HIV-positive individuals from $53 \%$ to $63 \%$ and $65 \%$ by 4 years and 10 years respectively, and population viral load suppression (among all HIV-positive individuals) from $56 \%$ to $65 \%$ and $67 \%$ by 4 years and 10 years respectively.

Compared to the baseline rate, the targeted VMMC intervention would further reduce HIV incidence compared to the non-targeted VMMC intervention (reduction overall: $28 \%$ and $25 \%$ respectively by 4 years, $36 \%$ and $28 \%$ respectively by 10 years). Although the targeted VMMC scenario would provide greater reduction in HIV incidence than the non-targeted VMMC scenario $(15 \%$ and $8 \%$ respectively compared "No change" scenario by 4 years), the latter would provide a greater reduction in incidence per additional number of circumcisions performed (32\% per additional number of circumcisions performed).

Compared to the baseline rate, the targeted PrEP intervention at 40\% among 15-24-year-old HIVuninfected women would further reduce HIV incidence compared to the non-targeted PrEP intervention (reduction overall: $32 \%$ vs. $28 \%$ respectively by 4 years and $37 \%$ vs. $30 \%$ respectively by 10 years). The targeted scenario would provide a slightly greater reduction ( $3 \%$ by 4 years) in incidence per additional number of PrEP use. The targeted PrEP intervention at 20\% among 15-24-year-old HIV-uninfected women had similar impacts to the nontargeted PrEP intervention.

Compared to the baseline rate, the "ART at $\mathrm{CD} 4<500$ " intervention (i.e. initiation at $C D 4 \leq 500$ cells $/ \mathrm{mm}^{3}$ plus PMTCT option $\mathrm{B}+$, with baseline VMMC) would reduce HIV incidence by $30 \%$ overall by 4 years and $41 \%$ by 10 years. The reduction in HIV incidence would be higher in women than in men ( $31 \%$ vs. $23 \%$ by 4 years and $42 \%$ vs. $29 \%$ by 10 years). The reduction would be higher in the first two age groups (around 35\% in the age groups $15-24$ years and $25-34$ years vs. $27 \%$ in the age group $35-59$ years by 4 years and around $49 \%$ vs. $37 \%$ by 10 years). This intervention would lead to a population viral load suppression of $69 \%$ by 4 years and $75 \%$ by 10 years.

Combining "ART at CD4<500" intervention with VMMC targeted to young men would have a higher impact in reducing the baseline incidence compared to "ART at CD4<500" intervention with non-targeted VMMC overall (34\% vs. $31 \%$ respectively) and among men (32\% vs. $26 \%$; Table 2). By 10 years, combination of "ART at CD4<500" intervention with VMMC targeted to young men would also have a higher impact in reducing the baseline incidence compared to "ART at CD4<500" intervention with non-targeted VMMC overall (49\% vs. $43 \%$ respectively) and among men (45\% vs. $33 \%$ ).

The "ART for all" intervention would lead to a greater population viral load suppression $(73 \%$ and $80 \%$ by 4 and 10 years respectively) and a greater impact on reducing HIV incidence rate (overall $36 \%$ and $51 \%$ by 4 and 10 years respectively). The reduction in HIV incidence would be slightly higher in women than in men $35 \%$ vs. $33 \%$ by 4 years and $51 \%$ vs. $44 \%$ by 10 years). The reduction would be higher in the first two age groups (around $40 \%$ in the age groups $15-24$ and $25-34$ years vs. $34 \%$ in 
Table 2 HIV incidence rates per 100 person-years (and percentage reduction compared to the baseline incidence rate), prevalence (\%), and population viral load suppression (\%) after four years of interventions

\begin{tabular}{|c|c|c|c|c|c|c|c|c|}
\hline & \multicolumn{6}{|l|}{ Incidence rates } & \multirow{2}{*}{$\begin{array}{l}\text { Overall } \\
\text { prevalence }\end{array}$} & \multirow{2}{*}{$\begin{array}{l}\text { Overall } \\
\text { population } \\
\text { viral load } \\
\text { suppression }\end{array}$} \\
\hline & $\begin{array}{l}\text { Overall } \\
\text { (baseline: 2.25) }\end{array}$ & $\begin{array}{l}\text { Men } \\
\text { (baseline: 1.15) }\end{array}$ & $\begin{array}{l}\text { Women } \\
\text { (baseline: 3.28) }\end{array}$ & $\begin{array}{l}\text { Aged } 15-24 \text { years } \\
\text { (baseline: } 1.76 \text { ) }\end{array}$ & $\begin{array}{l}\text { Aged } 25-34 \text { years } \\
\text { (baseline: } 4.58 \text { ) }\end{array}$ & $\begin{array}{l}\text { Aged } 35-59 \text { years } \\
\text { (baseline: } 1.56 \text { ) }\end{array}$ & & \\
\hline$\overline{\text { No change }^{a}}$ & $1.70(-24 \%)$ & $1.01(-11 \%)$ & $2.40(-27 \%)$ & $1.21(-31 \%)$ & $3.24(-29 \%)$ & $1.28(-18 \%)$ & 26.5 & 65.1 \\
\hline \multicolumn{8}{|l|}{ ART at CD4<500 at: } & $55 \%, 75 \%, 85 \%^{\mathrm{b}}$ \\
\hline $\begin{array}{l}\text { + Baseline VMMC } \\
\text { 15-24 years: } 26 \% \\
\text { 25-34 years: } 21 \% \\
\text { 35-59 years: } 19 \%\end{array}$ & $1.57(-30 \%)$ & $0.88(-23 \%)$ & $2.27(-31 \%)$ & $1.13(-36 \%)$ & $2.98(-35 \%)$ & $1.14(-27 \%)$ & 26.3 & 69.3 \\
\hline \multicolumn{8}{|l|}{ 15-24 years: 70\% } & 69.4 \\
\hline $\begin{array}{l}\text { + Increased VMMC at: } \\
\text { 15-24 years: } 35 \% \\
\text { 25-34 years: } 25 \% \\
\text { 35-59 years: } 20 \%\end{array}$ & $1.55(-31 \%)$ & $0.85(-26 \%)$ & $2.25(-31 \%)$ & $1.12(-36 \%)$ & $2.93(-36 \%)$ & $1.13(-28 \%)$ & 26.3 & 69.3 \\
\hline \multicolumn{9}{|l|}{ ART for all at: } \\
\hline $\begin{array}{l}\text { + Baseline VMMC } \\
\text { 15-24 years: } 26 \% \\
\text { 25-34 years: } 21 \% \\
\text { 35-59 years: } 19 \%\end{array}$ & $1.44(-36 \%)$ & $0.77(-33 \%)$ & $2.12(-35 \%)$ & $1.05(-40 \%)$ & $2.74(-40 \%)$ & $1.02(-34 \%)$ & 26.2 & 72.8 \\
\hline \multicolumn{8}{|l|}{ 15-24 years: 70\% } & 72.9 \\
\hline $\begin{array}{l}\text { + Increased VMMC at } \\
\text { 15-24 years: } 35 \% \\
\text { 25-34 years: } 25 \% \\
\text { 35-59 years: } 20 \%\end{array}$ & $1.42(-37 \%)$ & $0.74(-35 \%)$ & $2.11(-36 \%)$ & $1.04(-41 \%)$ & $2.69(-41 \%)$ & $1.01(-35 \%)$ & 26.1 & 72.8 \\
\hline \multicolumn{9}{|l|}{ ART for all at: } \\
\hline $\begin{array}{l}\text { + Increased PrEP at: } \\
\text { 15-24 years: } 20 \%\end{array}$ & $1.36(-40 \%)$ & $0.76(-34 \%)$ & $1.97(-40 \%)$ & $0.96(-46 \%)$ & $2.62(-43 \%)$ & $1.01(-35 \%)$ & 26.1 & 72.9 \\
\hline $\begin{array}{l}+ \text { Increased PrEP at: } \\
\text { 15-24 years: } 40 \%\end{array}$ & $1.28(-43 \%)$ & $0.75(-35 \%)$ & $1.82(-45 \%)$ & $0.86(-51 \%)$ & $2.50(-45 \%)$ & $1.00(-36 \%)$ & 25.9 & 73.1 \\
\hline $\begin{array}{c}+ \text { Increased PrEP at: } \\
\text { 15-24 years: } 15 \% \\
\text { 25-34 years: } 10 \% \\
\text { 35-59 years: } 5 \%\end{array}$ & $1.37(-39 \%)$ & $0.76(-34 \%)$ & $1.98(-40 \%)$ & $0.98(-44 \%)$ & $2.60(-43 \%)$ & $1.00(-36 \%)$ & 26.1 & 72.9 \\
\hline
\end{tabular}

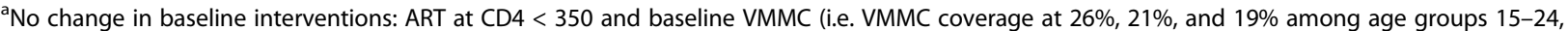
$25-34$, and 35-59 years respectively; see Methods section)

${ }^{\mathrm{b}}$ For age groups $15-24$ years, $25-34$ years and $35-59$ years respectively

the age group $35-59$ years by 4 years and around $58 \%$ vs. $50 \%$ by 10 years). Compared to "No change" scenario, "ART at CD4<500" and "ART for all" would further reduce HIV incidence rate by $8 \%$ and $15 \%$ by 4 years, respectively. Dividing these reductions to the additional number of person-years on ART, "ART for all" would provide $2 \%$ greater reduction in incidence per additional number of person-years on ART compared to "ART at CD4<500".

Combining "ART for all" intervention with VMMC targeted to young men would further reduce the incidence compared to "ART for all" intervention with non- 
targeted VMMC (overall reduction compared to baseline: $39 \%$ vs. $37 \%$ respectively by 4 years, and $57 \%$ vs. $53 \%$ respectively by 10 years). Combining "ART for all" intervention with PrEP targeted to young women would further reduce the incidence compared to "ART for all" intervention with non-targeted PrEP (overall: $40 \%$ and $43 \%$ depending on the targeted level vs. $39 \%$ by 4 years, and $55 \%$ and $59 \%$ depending on the targeted level vs. $54 \%$ by 10 years).

Figure 1 shows the reduction in HIV incidence compared to the baseline rate for "ART at CD $4<500$ " (black) or "ART for all" (grey) as a single intervention (top of the figure), combined to the targeted or non-targeted VMMC intervention (left), combined to the targeted or non-targeted PrEP intervention (bottom left), or combined to both VMMC and PrEP interventions with different scenarios. Combination of the three interventions (ART, VMMC, and PrEP) would have further impact on the overall incidence rate: from $35 \%$ to $41 \%$ reduction with "ART at CD4<500" and from $40 \%$ to $46 \%$ reduction with "ART for all" by 4 years depending on scenarios (Fig. 1 and Table 3). Combination of an ART intervention with age-targeted VMMC and/or PrEP interventions in young people would have the greatest impact on HIV incidence reduction (Fig. 2). Similar trends were observed by 10 years: combination of the three interventions (ART, VMMC, and PrEP) would have further impact on the overall incidence rate: from $46 \%$ to $57 \%$ reduction with "ART at CD $4<500$ " and from $56 \%$ to $64 \%$ reduction with "ART for all" depending on scenarios.
Reductions in HIV incidence were only slightly changed when varying the values of the mortality rates, and the comparisons between interventions remained unchanged (Additional file 1: Table S1).

The reduction in HIV incidence was lower when including a drop-out from ART in "No change" scenario (overall reduction compared to the baseline HIV incidence rate with an annual drop-out of $1.5 \%$ and $5 \%$ : $22 \%$ and $17 \%$ respectively by 4 years, $22 \%$ and $14 \%$ respectively by 10 years; Additional file 1: Table S2). The number of individuals to treat to achieve the target coverage for "ART at CD $4<500$ " and "ART for all" would be higher when including a drop-out rate than without; while HIV incidence reduction was similar by 4 and 10 years.

\section{Discussion}

We compared the potential impact of ART interventions and combined interventions on HIV incidence in a hyperendemic setting in KZN using age-specific targets for the ART, VMMC, and PrEP interventions, and agetargeted scenarios for the VMMC and PrEP interventions. We found that age-targeted interventions had a greater impact on incidence reduction than interventions without. Looking at the impact on the incidence of each intervention isolated, ART initiation regardless of CD4 count had the greatest impact. Our results are consistent with those from previous mathematical models applied to Sub-Saharan populations showing that substantial reduction in HIV incidence could be achieved

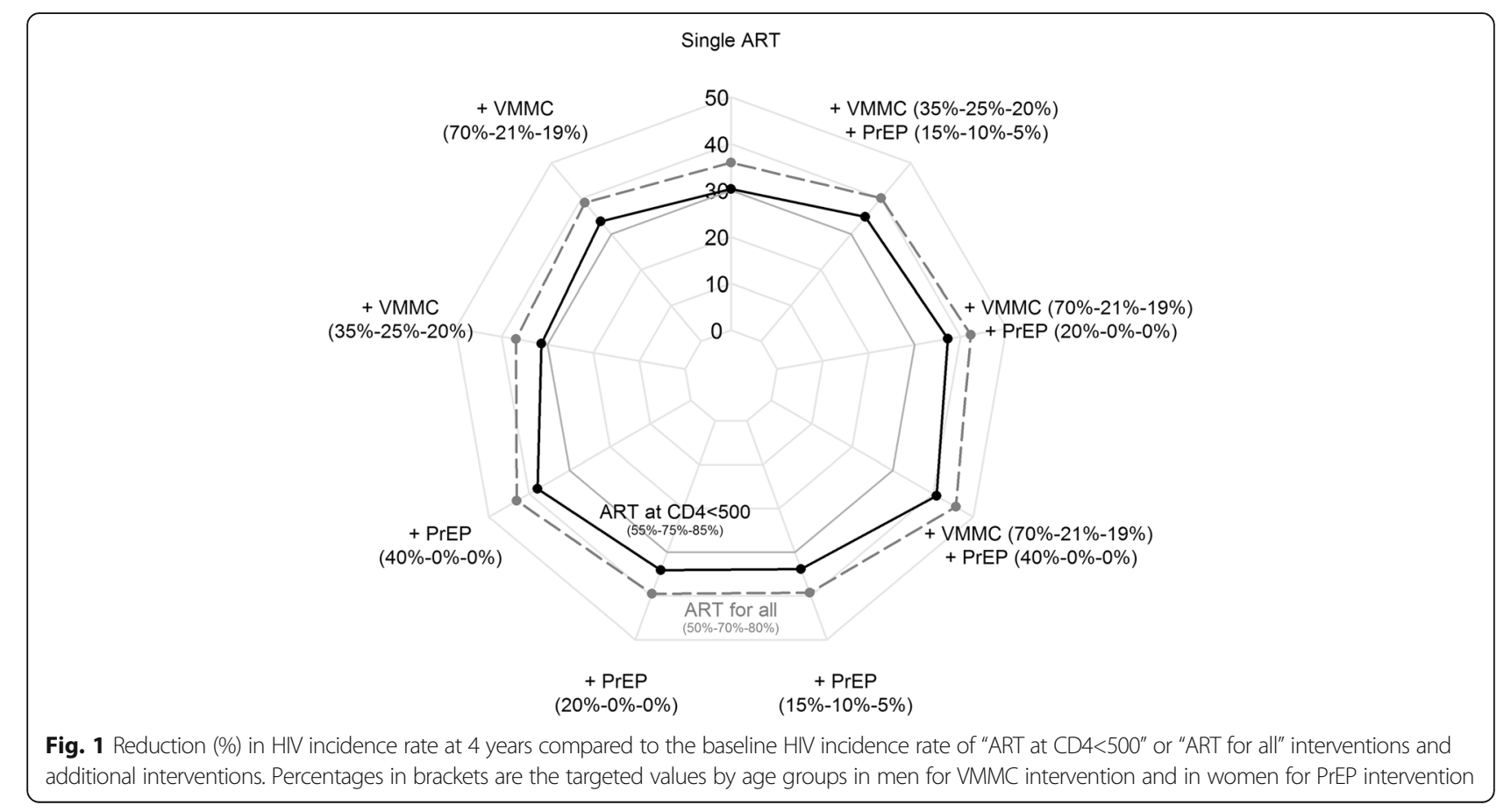


Table 3 Reduction (\%) in HIV incidence rate at 4 years compared to the baseline rate for an increased coverage of ART, VMMC and PrEP in different combinations

\begin{tabular}{|c|c|c|c|c|}
\hline & No PrEP & $\begin{array}{l}+ \text { PrEP } \\
\text { 15-24 years: } 40 \% \\
\text { 25-34 years: } 0 \% \\
\text { 35-59 years: } 0 \%\end{array}$ & $\begin{array}{l}\text { + PrEP } \\
\text { 15-24 years: } 20 \% \\
\text { 25-34 years: } 0 \% \\
\text { 35-59 years: } 0 \%\end{array}$ & $\begin{array}{l}\text { + PrEP } \\
\text { 15-24 years: 15\% } \\
\text { 25-34 years: 10\% } \\
\text { 35-59 years: 5\% }\end{array}$ \\
\hline No change $^{a}$ & $24 \%$ & $32 \%$ & $28 \%$ & $28 \%$ \\
\hline \multicolumn{5}{|l|}{ ART at $C D 4<500$ at } \\
\hline \multicolumn{5}{|l|}{$15-24$ years: $55 \%$} \\
\hline \multicolumn{5}{|l|}{ 25-34 years: 75\% } \\
\hline \multicolumn{5}{|l|}{ 35-59 years: 85\% } \\
\hline + Baseline VMMC & $30 \%$ & $38 \%$ & $34 \%$ & $34 \%$ \\
\hline \multicolumn{5}{|l|}{$15-24$ years: $26 \%$} \\
\hline \multicolumn{5}{|l|}{$25-34$ years: $21 \%$} \\
\hline \multicolumn{5}{|l|}{$35-59$ years: $19 \%$} \\
\hline+ Increased VMMC at & $34 \%$ & $41 \%$ & $37 \%$ & $37 \%$ \\
\hline \multicolumn{5}{|l|}{$15-24$ years: $70 \%$} \\
\hline+ Increased VMMC at & $31 \%$ & $39 \%$ & $35 \%$ & $35 \%$ \\
\hline \multicolumn{5}{|l|}{$15-24$ years: $35 \%$} \\
\hline \multicolumn{5}{|l|}{$25-34$ years: $25 \%$} \\
\hline \multicolumn{5}{|l|}{$35-59$ years: $20 \%$} \\
\hline \multicolumn{5}{|l|}{ ART for all at } \\
\hline \multicolumn{5}{|l|}{$15-24$ years: $50 \%$} \\
\hline \multicolumn{5}{|l|}{ 25-34 years: 70\% } \\
\hline \multicolumn{5}{|l|}{$35-59$ years: $80 \%$} \\
\hline + Baseline VMMC & $36 \%$ & $43 \%$ & $40 \%$ & $39 \%$ \\
\hline \multicolumn{5}{|l|}{$15-24$ years: $26 \%$} \\
\hline \multicolumn{5}{|l|}{$25-34$ years: $21 \%$} \\
\hline \multicolumn{5}{|l|}{$35-59$ years: $19 \%$} \\
\hline+ Increased VMMC at & $39 \%$ & $46 \%$ & $42 \%$ & $42 \%$ \\
\hline \multicolumn{5}{|l|}{ 15-24 years: 70\% } \\
\hline + Increased VMMC at & $37 \%$ & $44 \%$ & $40 \%$ & $40 \%$ \\
\hline \multicolumn{5}{|l|}{$15-24$ years: $35 \%$} \\
\hline \multicolumn{5}{|l|}{$25-34$ years: $25 \%$} \\
\hline $35-59$ years: $20 \%$ & & & & \\
\hline
\end{tabular}

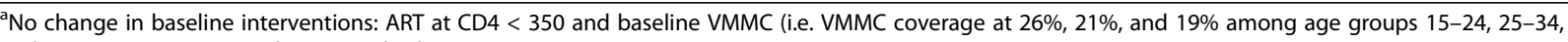
and 35-59 years respectively; see Methods section)

with scale-up of ART (especially within a 'test and treat' strategy with extended ART eligibility) [20-28].

Recently, combination HIV prevention interventions have received increasing attention [29-31] although little is known about the dynamics of combining various interventions. Mathematical modelling has thus been using to assess the potential impact of combined interventions on HIV incidence in several settings [13, 32-38]. Our results showed that extended criteria for ART initiation in combination with moderate VMMC and PrEP coverage would further decrease incidence rate compared to ART as a single intervention. A recent modelling of data from KZN showed that HIV incidence rate would be reduced by around $60 \%$ within four years with a combination of four interventions: increasing the coverage of testing and counselling, reducing risky behaviour, increasing the coverage of VMMC, and increase ART coverage with extending eligibility to all HIV-positive individuals [37]. Cori et al. estimated that in South Africa a combination of increasing home-based voluntary testing and counselling, increasing VMMC coverage, and increasing ART coverage with a treat-all strategy over three years would lead to a $60 \%$ reduction [38]. 


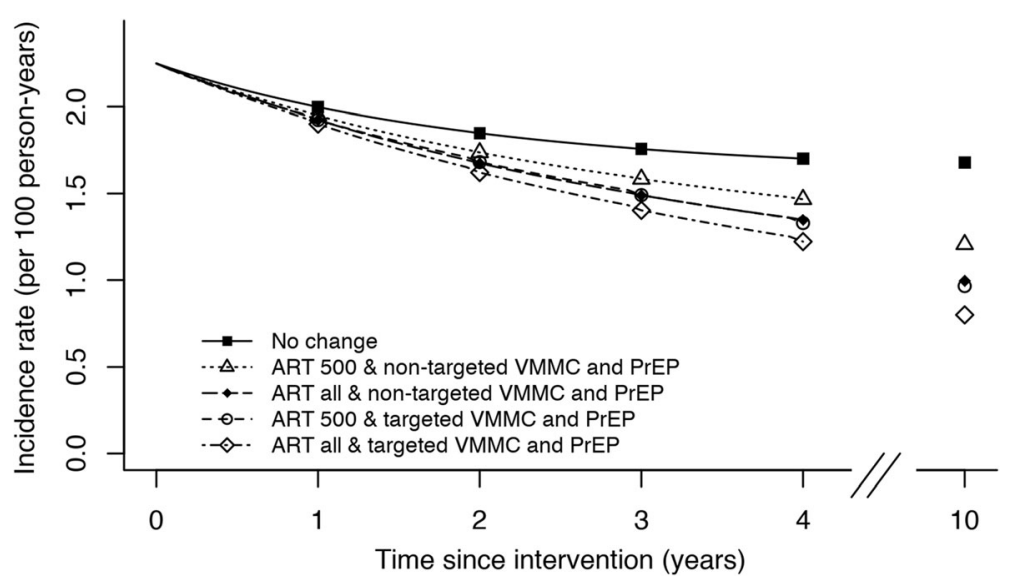

Fig. 2 Overall HIV incidence rate for "No change" scenario and combined interventions. In this figure, the targeted PrEP scenario is the scenario with $40 \%$ of women aged 15-24 years using PrEP

Cremin et al. showed that combination of early ART, circumcision, and PrEP at relatively high levels would reduce $\mathrm{HIV}$ incidence in KZN as high as $84 \%$ over 10 years compared to the "status quo" (with ART eligibility at $200 \mathrm{CD} 4$ cell count $/ \mathrm{mm}^{3}$ ) [33].

Our results showed that, among the various scenarios considered, the combination of ART for all with PrEP targeted to $15-24$-year-old women at $40 \%$ would be the most effective scenario to reduce overall incidence, incidence among women and among young adults. The most effective scenario to reduce incidence in men would be the combination of ART for all with VMMC at $70 \%$ among men aged 15-24 years. However, achieving these coverage rates may be difficult, the combination of ART for all with non-age-targeted VMMC or agetargeted PrEP at $20 \%$ coverage would be more feasible and also effective in reducing incidence rates.

These interventions would require extending ART eligibility to all HIV-positive individuals, requiring adequate prior coverage in each step of the care cascade. The latter is critical in a treatment-as-prevention interventions: the first results of the ANRS 12249 TasP trial in northern KZN did not show a statistically significant difference in HIV incidence over a four-year period between the intervention group (ART initiation irrespective of CD4) and the control group (ART initiation according to the national guidelines) which may be explained by the low linkage to care of newly diagnosed individuals in both arms (47\% within 12 months) and the small difference in ART coverage between arms (45\% in the intervention arm vs. $43 \%$ in the control arm) while ART eligibility should have been higher in the intervention arm than in the control arm [39]. In Mbongolwane and Eshowe, the achievements obtained by MSF and KZN department of Health interventions in population testing [40] and extension of ART eligibility from CD4 $\leq 350$ to $\leq 500$ cells $/ \mathrm{mm}^{3}[40,41]$ are promising for extending ART to all HIV-positive individuals. Indeed, program data showed acceptability from individuals with CD4 351-500 cells $/ \mathrm{mm}^{3}$ to initiate and remain on ART (70\% of individuals initiated on ART after testing positive with CD4 counts $351-500$ and $>80 \%$ retention in care at 12 months) and without negative effects for individuals with $\mathrm{CD} 4<350$ cells $/ \mathrm{mm}^{3}$. However, strategies should be reinforced or implemented to ensure high adherence to ART to achieve high level of viral suppression; level of viral suppression among individuals on ART being a key parameter to ensure the success of a treatment-as-prevention strategy [34].

Our results showed that, over a four-year period, population viral load suppression would reach $69 \%$ under ART at CD4<500 and $73 \%$ under ART for all reaching UNAIDS targets $(90 \% * 90 \% * 90 \%)$. These results have been obtained assuming steady proportions of viral load suppression over time among HIV-positive individuals, and particularly among those on ART. Few modelling studies have calculated this metric [13, 34], mainly due to lack of data on levels of viral suppression at population level. However, this is an interesting metric since it has been shown to be negatively associated with incidence [42-44] and can be estimated more easily than incidence in population. Moreover, this metric will be increasingly used with the current implementation of viral load monitoring in Sub-Saharan Africa.

The PrEP intervention was included here despite previous mixed results in Sub-Saharan Africa (discrepancies explained by differences in adherence levels) [45] and its costs. If PrEP is implemented, strategies should be developed to ensure high levels of adherence and therefore effectiveness in reducing HIV acquisition risk. New technologies currently assessed in clinical trials such as vaginal rings [46] or 
long-acting injectable ARV [47] could improve effectiveness levels.

Previous modelling studies showed that extending ART to higher CD4 count levels would be cost-effective $[21,48]$. PrEP as an additional intervention, following extension of criteria for ART to higher CD4 count levels and increase in ART coverage (and increasing VMMC coverage), would be cost-effective when prioritized to key populations or persons with highest risks or incidence [28, 49-52]. High opportunity costs could be expected if PrEP is funded to the detriment of other more cost-effective HIV prevention interventions.

Our analysis had some limitations. First, our model assumed homogeneous (random) mixing among men and women between age groups. The reduction in HIV incidence could be overestimated if individuals in a given age group made relationships with individuals at higher risk whereas underestimated if individuals in a given age group made relationships with individuals at lower risk. Recent studies have reported complex agemixing sexual patterns [53-55]. However, since the assumption of homogeneous mixing between age groups was made for each intervention, similar relative trends could be expected when comparing interventions. Second, our model does not account for nonheterosexual HIV transmission. However, in South Africa, overall HIV transmission does not seem to be substantially driven by men who have sex with men $[56,57]$, yet they can (directly or indirectly) benefit from the interventions modelled or focused interventions. Third, the steps of the cascade of care were implicitly modelled; however, the success of an ART intervention requires high levels in each step of the cascade of care and, as above-mentioned, strategies must be strengthened or implemented to reach high levels. Fourth, the development and transmission of drug resistance in HIV-positive individuals on ART or in those acquiring HIV while using PrEP were not modelled. Non-nucleoside reverse transcriptase inhibitor resistance levels were estimated at $14 \%$ among patients initiating and 38\% among those re-initiating ART in South Africa [58]. These levels are likely to increase with the scale-up of ART and extension of ART eligibility criteria [59-61]. HIV drug resistance could substantially increase the number of AIDS deaths, the number of new infections, and ART program costs [62], but the benefits of ART interventions would not be counterbalanced by the increase in HIV drug resistance levels $[63,64]$. Moreover, several modelling studies have showed that the majority of resistance cases would be rather due to ART than to PrEP, ART coverage being higher than PrEP coverage $[65,66]$. South African ART guidelines recommended the use of viral load for monitoring patients on ART [67] which could allow early detection of failure and decrease resistance [68]. Observational data on the development and transmission of drug resistance in HIV-positive individuals on ART under extended ART eligibility would be of high interest. Lastly, we compared age-specific targets and agetargeted interventions. However, depending on the study area (e.g. a whole country or a district), interventions could target other population groups (e.g. by geography or risk group) and with the additional use of cost analyses [32, 35]. Moreover, we focused on the combination of ART, VMMC, and PrEP, although combination HIV prevention interventions include a wide range of interventions which could further reduce the number of new HIV infections.

\section{Conclusions}

In Mbongolwane and Eshowe, implementation of the new South African guidelines for ART initiation (regardless of CD4 count) would accelerate reduction in incidence. Combined strategies, particularly if targeted to young people, would further reduce the HIV incidence in adult population.

\section{Additional file}

Additional file 1: Technical appendix and supplementary results. (PDF 639 kb)

\section{Abbreviations}

AIDS: Acquired immunodeficiency syndrome; ART: Antiretroviral therapy; HIV: Human immunodeficiency virus; KZN: KwaZulu-Natal; MHIPS: Mbongolwane and Eshowe HIV Impact in Population Survey; MSF: Médecins Sans Frontières (Doctors Without Borders); PMTCT: Prevention of mother-to-child transmission; PrEP: Pre-exposure prophylaxis; UNAIDS: Joint United Nations Programme on HIV and AIDS;

VMMC: Voluntary medical male circumcision; WHO: World Health Organization

\section{Acknowledgements}

The authors thank the participants and the community of Mbongolwane and Eshowe for their collaboration. We are grateful to the Epicentre study field team for their work and the Médecins Sans Frontières field team for their support.

\section{Funding}

Author SB was financially supported by Agence Nationale de Recherche sur le SIDA et les hépatites virales, ANRS (France REcherche Nord \& sud SIDA-HIV Hépatites: FRENSH), France.

\section{Availability of data and materials}

The datasets used and/or analysed during the current study are available from the corresponding author on reasonable request.

\section{Authors' contributions}

$\mathrm{SB}, \mathrm{HH}, \mathrm{BR}, \mathrm{TE}, \mathrm{AS}, \mathrm{JFE}$, and RE conceived and designed the experiments. SB, $\mathrm{BR}$, and RE performed the experiments. SB, HH, BR, TE, AS, JFE, and RE analysed the results. $S B, H H, B R$, and RE wrote the first draft of the manuscript. SB, HH, BR, TE, AS, JFE, and RE contributed to the writing of the manuscript. All authors read and approved final manuscript.

Ethics approval and consent to participate

The protocol of MHIPS was approved by the University of Cape Town Human Research Ethics Committee (HREC), the Health Research Committee 
of the Health Research and Knowledge Management Unit of KZN DOH, and the "Comité de Protection des Personnes", Paris, France. Written informed consent was sought prior to the enrolment of participants.

\section{Consent for publication}

Not applicable.

\section{Competing interests}

The authors declare that they have no competing interests.

\section{Publisher's Note}

Springer Nature remains neutral with regard to jurisdictional claims in published maps and institutional affiliations.

\begin{abstract}
Author details
'Service de Biostatistique, Hospices Civils de Lyon, F-69003 Lyon, France. ${ }^{2}$ Université de Lyon, F-69000 Lyon, France. ${ }^{3}$ Université Lyon 1, F-69100 Villeurbanne, France. ${ }^{4}$ CNRS UMR 5558, Equipe Biostatistique-Santé, Laboratoire de Biométrie et Biologie Evolutive, F-69100 Villeurbanne, France. ${ }^{5}$ Epicentre, F-75011 Paris, France. ${ }^{6}$ Médecins Sans Frontières, Cape Town, South Africa. ${ }^{7}$ IRD UMI 233, INSERM U1175, Université de Montpellier, Unité TransVIHMI, F-34000 Montpellier, France.
\end{abstract}

Received: 4 April 2017 Accepted: 18 July 2017

Published online: 26 July 2017

\section{References}

1. Shisana O, Rehle T, Simbayi L, Zuma K, Jooste S, Zungu N, Labadarios D, Onoya D. South African National HIV Prevalence, Incidence and Behaviour Survey, 2012. Cape Town: HSRC Press; 2014.

2. Joint United Nations Programme on HIV/AIDS (UNAIDS). 90-90-90 An ambitious treatment target to help end the AIDS epidemic. Geneva: Joint United Nations Programme on HIV/AIDS (UNAIDS); 2014.

3. Castelnuovo B, Musaazi J, Musomba R, Ratanshi RP, Kiragga AN. Quantifying retention during pre-antiretroviral treatment in a large urban clinic in Uganda. BMC Infect Dis. 2015;15:252.

4. Jean K, Puren A, Cutler E, Singh B, Bouscaillou J, Rain-Taljaard R, Taljaard D, Gouws E, Lissouba P, Lewis DA, et al. Level of viral suppression and the cascade of HIV care in a South African semi-urban setting in 2012. AIDS. 2016;30(13):2107-16

5. MacLeod WB, Fraser N, Bor J, Shubber Z, Carmona S, Pillay Y, Gorgens M: Analysis of age- and sex-specific HIV care cascades in South Africa suggests unequal progress towards UNAIDS 90-90-90 treatment targets. 21st International AIDS Conference: 18-22 July 2016; Durban, South Africa.

6. Takuva S, Brown A, Macleod W, Pillay Y, Delpech V, Puren A: Disparities in engagement within HIV care in South Africa. Conference on Retroviruses and Opportunistic Infections: 2015; Seattle, USA.

7. WHO Regional Office for Africa. Progress in scaling up voluntary medical male circumcision for HIV prevention in East and Southern Africa: 2012. Brazzaville: WHO Regional Office for Africa; 2013.

8. Joint United Nations Programme on HIV/AIDS (UNAIDS). The gap report. Geneva: Joint United Nations Programme on HIV/AIDS (UNAIDS); 2014.

9. Harrison A, Colvin CJ, Kuo C, Swartz A, Lurie M. Sustained high HIV incidence in young women in Southern Africa: social, behavioral, and structural factors and emerging intervention approaches. Curr Hiv-Aids Rep. 2015;12(2):207-15.

10. Statistics South Africa. Census 2011 Statistical release - P0301.4. Pretoria: Statistics South Africa; 2012.

11. Huerga $H$, Van Cutsem $G$, Ben Farhat J, Reid M, Bouhenia M, Maman D, Wiesner L, Etard JF, Ellman T. Who needs to be targeted for HIV testing and treatment in KwaZulu-Natal? Results from a population-based survey. J Acquir Immune Defic Syndr. 2016;73(4):411-8.

12. Blaizot S, Riche B, Maman D, Mukui I, Kirubi B, Etard JF, Ecochard R. Estimation and short-term prediction of the course of the hiv epidemic using demographic and health survey methodology-like data. PLoS One. 2015;10(6):e0130387

13. Blaizot S, Maman D, Riche B, Mukui I, Kirubi B, Ecochard R, Etard JF. Potential impact of multiple interventions on HIV incidence in a hyperendemic region in Western Kenya: a modelling study. BMC Infect Dis. 2016;16:189.

14. Nyirenda M, Hosegood V, Barnighausen T, Newell ML. Mortality levels and trends by HIV serostatus in rural South Africa. AIDS. 2007;21(Suppl 6):S73-9.
15. Auvert B, Taljaard D, Lagarde E, Sobngwi-Tambekou J, Sitta R, Puren A. Randomized, controlled intervention trial of male circumcision for reduction of HIV infection risk: the ANRS 1265 Trial. PLoS Med. 2005;2(11):e298.

16. Bailey RC, Moses S, Parker CB, Agot K, Maclean I, Krieger JN, Williams CF, Campbell RT, Ndinya-Achola JO. Male circumcision for HIV prevention in young men in Kisumu, Kenya: a randomised controlled trial. Lancet. 2007; 369(9562):643-56.

17. Gray RH, Kigozi G, Serwadda D, Makumbi F, Watya S, Nalugoda F, Kiwanuka N, Moulton LH, Chaudhary MA, Chen MZ, et al. Male circumcision for HIV prevention in men in Rakai, Uganda: a randomised trial. Lancet. 2007; 369(9562):657-66.

18. World Health Organization. Guideline on when to start antiretroviral therapy and on pre-exposure prophylaxis for HIV. Geneva: World Health Organization; 2015.

19. Cohen MS, Chen YQ, McCauley M, Gamble T, Hosseinipour MC, Kumarasamy N, Hakim JG, Kumwenda J, Grinsztejn B, Pilotto JH, et al. Prevention of HIV-1 infection with early antiretroviral therapy. N Engl J Med. 2011;365(6):493-505

20. Granich RM, Gilks CF, Dye C, De Cock KM, Williams BG. Universal voluntary HIV testing with immediate antiretroviral therapy as a strategy for elimination of HIV transmission: a mathematical model. Lancet. 2009; 373(9657):48-57.

21. Eaton JW, Menzies NA, Stover J, Cambiano V, Chindelevitch L, Cori A, Hontelez JAC, Humair S, Kerr CC, Klein DJ, et al. Health benefits, costs, and cost-effectiveness of earlier eligibility for adult antiretroviral therapy and expanded treatment coverage: a combined analysis of 12 mathematical models. Lancet Glob Health. 2014;2(1):E23-34.

22. Abuelezam NN, McCormick AW, Fussell T, Afriyie AN, Wood R, DeGruttola V, Freedberg KA, Lipsitch M, Seage GR. Can the heterosexual HIV epidemic be eliminated in South Africa using combination prevention? A modeling analysis. Am J Epidemiol. 2016;184(3):239-48.

23. Dodd PJ, Garnett GP, Hallett TB. Examining the promise of HIV elimination by 'test and treat' in hyperendemic settings. AIDS. 2010;24(5):729-U128.

24. Eaton JW, Johnson LF, Salomon JA, Barnighausen T, Bendavid E, Bershteyn A, Bloom DE, Cambiano V, Fraser C, Hontelez JAC, et al. HIV treatment as prevention: systematic comparison of mathematical models of the potential impact of antiretroviral therapy on HIV incidence in South Africa. PLoS Med. 2012;9(7):e1001245.

25. Hontelez JAC, Lurie MN, Barnighausen T, Bakker R, Baltussen R, Tanser F, Hallett TB, Newell ML, de Vlas SJ. Elimination of HIV in South Africa through expanded access to antiretroviral therapy: a model comparison study. PLoS Med. 2013;10(10):e1001534.

26. Johnson LF, Dorrington RE. Modelling the demographic impact of HIV/AIDS in South Africa and the likely impact of interventions. Demogr Res. 2006;14:541-73.

27. Johnson LF, White PJ. A review of mathematical models of HIV/AIDS interventions and their implications for policy. Sex Transm Infect. 2011;87(7):629-34

28. Long EF, Stavert RR. Portfolios of biomedical HIV interventions in South Africa: a cost-effectiveness analysis. J Gen Intern Med. 2013;28(10):1294-301.

29. Joint United Nations Programme on HIV/AIDS (UNAIDS). Combination HIV prevention: tailoring and coordinating biomedical, behavioural and structural strategies to reduce new HIV infections. A UNAIDS Discussion Paper. Geneva: Joint United Nations Programme on HIV/AIDS (UNAIDS); 2010.

30. Brown G, Reeders D, Dowsett GW, Ellard J, Carman M, Hendry N, Wallace J. Investigating combination HIV prevention: isolated interventions or complex system. J Int AIDS Soc. 2015;18:20499.

31. Shanaube K, Bock P. Innovative strategies for scale up of effective combination HIV prevention interventions in Sub-Saharan Africa. Curr HivAids Rep. 2015;12(2):231-7.

32. Anderson SJ, Cherutich P, Kilonzo N, Cremin I, Fecht D, Kimanga D, Harper M, Masha RL, Ngongo PB, Maina W, et al. Maximising the effect of combination HIV prevention through prioritisation of the people and places in greatest need: a modelling study. Lancet. 2014;384(9939):249-56.

33. Cremin I, Alsallaq R, Dybul M, Piot P, Garnett G, Hallett TB. The new role of antiretrovirals in combination HIV prevention: a mathematical modelling analysis. AIDS. 2013;27(3):447-58.

34. Johnson LF, Chiu C, Myer L, Davies MA, Dorrington RE, Bekker LG, Boulle A, Meyer-Rath G. Prospects for HIV control in South Africa: a model-based analysis. Glob Health Action. 2016;9 
35. McGillen JB, Anderson SJ, Dybul MR, Hallett TB. Optimum resource allocation to reduce HIV incidence across sub-Saharan Africa: a mathematical modelling study. Lancet Hiv. 2016;3(9):E441-8.

36. Smith JA, Anderson SJ, Harris KL, McGillen JB, Lee E, Garnett GP, Hallett TB. Maximising HIV prevention by balancing the opportunities of today with the promises of tomorrow: a modelling study. Lancet HIV. 2016;3(7):e289-96.

37. Alsallaq RA, Baeten JM, Celum CL, Hughes JP, Abu-Raddad LJ, Barnabas RV, Hallett TB. Understanding the potential impact of a combination HIV prevention intervention in a hyper-endemic community. PLoS One. 2013; 8(1):e54575.

38. Cori A, Ayles H, Beyers N, Schaap A, Floyd S, Sabapathy K, Eaton JW, Hauck K, Smith P, Griffith S, et al. HPTN 071 (POPART): a cluster-randomized trial of the population impact of an HIV combination prevention intervention including universal testing and treatment: mathematical model. PLoS One. 2014;9(1):e84511.

39. Iwuji C, Orne-Gliemann J, Balestre E, Larmarange J, Thiebaut R, Tanser F, Okesola N, Makowa T, Dreyer J, Herbst K et al: The impact of universal test and treat on HIV incidence in a rural South African population. 21st International AIDS conference: 18-22 July 2016; Durban, South Africa.

40. Médecins Sans Frontières. Bending the curves of the HIV/TB epidemic in KwaZulu-Natal. 2016. URL: https://www.msf.org.za/about-us/publications/ reports/bending-curves-hivtb-epidemic-kwazulu-natal. Accessed August 2016

41. Steele SJ, Arellano F, Ellman T, Shroufi A, Van Cutsem G. Extended ART initiation criteria can be implemented successfully in rural South Africa. 21st International AIDS Conference: 18-22 July 2016; Durban, South Africa.

42. Wood E, Kerr T, Marshall BDL, Li K, Zhang R, Hogg RS, Harrigan PR, Montaner JSG. Longitudinal community plasma HIV-1 RNA concentrations and incidence of HIV-1 among injecting drug users: prospective cohort study. Brit Med J. 2009;338:b1649.

43. Das M, Chu PL, Santos GM, Scheer S, Vittinghoff E, McFarland W, Colfax GN. Decreases in community viral load are accompanied by reductions in new HIV infections in San Francisco. PLoS One. 2010;5(6):e11068.

44. Castel AD, Befus M, Willis S, Griffin A, West T, Hader S, Greenberg AE. Use of the community viral load as a population-based biomarker of HIV burden. AIDS. 2012;26(3):345-53.

45. Baeten JM, Haberer JE, Liu AY, Sista N. Preexposure prophylaxis for HIV prevention: where have we been and where are we going? J Acquir Immune Defic Syndr. 2013;63(Suppl 2):S122-9.

46. Baeten JM, Palanee-Phillips T, Brown ER, Schwartz K, Soto-Torres LE, Govender V, Mgodi NM, Matovu Kiweewa F, Nair G, Mhlanga F, et al. Use of a vaginal ring containing dapivirine for HIV-1 prevention in women. $\mathrm{N}$ Engl J Med. 2016;375(22):2121-32.

47. Jackson A, McGowan I. Long-acting rilpivirine for HIV prevention. Curr Opin HIV AIDS. 2015;10(4):253-7.

48. Hontelez JA, Chang AY, Ogbuoji O, de Vlas SJ, Barnighausen T, Atun R. Changing HIV treatment eligibility under health system constraints in subSaharan Africa: investment needs, population health gains, and costeffectiveness. AIDS. 2016;30(15):2341-50.

49. Glaubius RL, Hood G, Penrose KJ, Parikh UM, Mellors JW, Bendavid E, Abbas UL. Cost-effectiveness of injectable preexposure prophylaxis for HIV prevention in South Africa. Clin Infect Dis. 2016;63(4):539-47.

50. Walensky RP, Jacobsen MM, Bekker LG, Parker RA, Wood R, Resch SC, Horstman NK, Freedberg KA, Paltiel AD. Potential clinical and economic value of long-acting preexposure prophylaxis for South African women at high-risk for HIV infection. J Infect Dis. 2016;213(10):1523-31.

51. Alistar SS, Grant PM, Bendavid E. Comparative effectiveness and costeffectiveness of antiretroviral therapy and pre-exposure prophylaxis for HIV prevention in South Africa. BMC Med. 2014;12:46.

52. Gomez GB, Borquez A, Case KK, Wheelock A, Vassall A, Hankins C. The cost and impact of scaling up pre-exposure prophylaxis for HIV prevention: a systematic review of cost-effectiveness modelling studies. PLoS Med. 2013; 10(3):e1001401.

53. Abdool Karim Q: Assessing data supporting HIV prevention approaches. 21st International AIDS Conference: 18-22 July 2016; Durban, South Africa.

54. Dellar RC, Dlamini S, Karim QA. Adolescent girls and young women: key populations for HIV epidemic control. J Int AIDS Soc. 2015;18:64-70.

55. Akullian A, Bershteyn A, Klein D, Vandormael A, Barnighausen T, Tanser F. Sexual partnership age pairings and risk of HIV acquisition in rural South Africa. AIDS. 2017;31(12):1755-64.
56. Gouws E, Cuchi P, I ICEH. Focusing the HIV response through estimating the major modes of HIV transmission: a multi-country analysis. Sex Transm Infect. 2012;88:176-85.

57. Mulongeni $P$, Johnson L. Epidemiological synergy: the role of heterosexual transmission in the spread of HIV among men who have sex with men in South Africa. 21st International AIDS Conference: 18-22 July 2016; Durban, South Africa.

58. National Institute for communicable diseases: Communicable Diseases Communiqué. 2016; 15. URL: http://nicd.ac.za/assets/files/ NICD\%20Communicable\%20Diseases\%20Communique_Mar2016_final.pdf. Accessed June 2017.

59. Nagelkerke NJD, Jha P, de Vlas SJ, Korenromp EL, Moses S, Blanchard JF, Plummer FA. Modelling HIV/AIDS epidemics in Botswana and India: impact of interventions to prevent transmission. B World Health Organ. 2002;80(2):89-96.

60. Blower S, Bodine E, Kahn J, McFarland W. The antiretroviral rollout and drug-resistant HIV in Africa: insights from empirical data and theoretical models. AIDS. 2005;19(1):1-14.

61. Garnett GP, Bartley L, Grassly NC, Anderson RM. Antiretroviral therapy to treat and prevent HIV/AIDS in resource-poor settings. Nat Med. 2002;8(7):651-4.

62. Phillips AN, Stover J, Cambiano V, Nakagawa F, Jordan MR, Pillay D, Doherty M, Revill P, Bertagnolio S. Impact of HIV drug resistance on HIV/AIDSassociated mortality, new infections, and antiretroviral therapy program costs in sub-Saharan Africa. J Infect Dis. 2017;215(9):1362-5

63. Cambiano V, Bertagnolio S, Jordan MR, Pillay D, Perriens JH, Venter F, Lundgren J, Phillips A. Predicted levels of HIV drug resistance: potential impact of expanding diagnosis, retention, and eligibility criteria for antiretroviral therapy initiation. AIDS. 2014;28(Suppl 1):S15-23.

64. Nichols BE, Sigaloff KC, Kityo C, Mandaliya K, Hamers RL, Bertagnolio S, Jordan MR, Boucher CA, Rinke de Wit TF, van de Vijver DA. Averted HIV infections due to expanded antiretroviral treatment eligibility offsets risk of transmitted drug resistance: a modeling study. AIDS. 2014;28(1):73-83.

65. Abbas UL, Glaubius R, Mubayi A, Hood G, Mellors JW. Antiretroviral therapy and pre-exposure prophylaxis: combined impact on HIV transmission and drug resistance in South Africa. J Infect Dis. 2013;208(2):224-34.

66. van de Vijver DAMC, Nichols BE, Abbas UL, Boucher CAB, Cambiano V, Eaton JW, Glaubius R, Lythgoe K, Mellors J, Phillips A, et al. Preexposure prophylaxis will have a limited impact on HIV-1 drug resistance in sub-Saharan Africa: a comparison of mathematical models. AIDS. 2013;27(18):2943-51.

67. National Department of Health, Republic of South Africa. National consolidated guidelines for the prevention of mother-to-child transmission of HIV (PMTCT) and the management of HIV in children, adolescents, and adults. Pretoria: National Department of Health, Republic of South Africa; 2015.

68. Phillips AN, Cambiano V, Miners A, Revill P, Pillay D, Lundgren JD, Bennett D, Raizes E, Nakagawa F, De Luca A, et al. Effectiveness and cost-effectiveness of potential responses to future high levels of transmitted HIV drug resistance in antiretroviral drug-naive populations beginning treatment: modelling study and economic analysis. Lancet HIV. 2014;1(2):e85-93.

\section{Submit your next manuscript to BioMed Central and we will help you at every step:}

- We accept pre-submission inquiries

- Our selector tool helps you to find the most relevant journal

- We provide round the clock customer support

- Convenient online submission

- Thorough peer review

- Inclusion in PubMed and all major indexing services

- Maximum visibility for your research

Submit your manuscript at www.biomedcentral.com/submit
) Biomed Central 